\title{
Correction: Zgura et al. Cytotoxicity, Antioxidant, Antibacterial, and Photocatalytic Activities of ZnO-CdS Powders. Materials 2020, 13, 182
}

\author{
Irina Zgura ${ }^{1, *(D)}$, Nicoleta Preda ${ }^{1, *}$, Monica Enculescu ${ }^{1}\left(\mathbb{D}\right.$, Lucian Diamandescu ${ }^{1}$, Catalin Negrila $^{1}$, \\ Mihaela Bacalum ${ }^{2}$ (D), Camelia Ungureanu ${ }^{3}$ and Marcela Elisabeta Barbinta-Patrascu ${ }^{4}$ (D)
}

1 National Institute of Materials Physics, Atomistilor 405A, 077125 Magurele, Romania; mdatcu@infim.ro (M.E.); ldiamandescu@gmail.com (L.D.); catalin.negrila@infim.ro (C.N.)

2 Department of Life and Environmental Physics, Horia Hulubei National Institute for Physics and Nuclear Engineering (IFIN-HH), Bucharest, 077125 Magurele, Romania; bmihaela@nipne.ro

3 Faculty of Applied Chemistry and Materials Science, University "Politehnica" of Bucharest, 1-7, Polizu Street, 011061 Bucharest, Romania; ungureanucamelia@gmail.com

4 Faculty of Physics, University of Bucharest, 405 Atomistilor Street, PO Box MG-11, Bucharest, 077125

Magurele, Romania; elipatras@gmail.com

* Correspondence: irina.zgura@infim.ro (I.Z.); nicol@infim.ro (N.P.)

check for

updates

Citation: Zgura, I.; Preda, N.;

Enculescu, M.; Diamandescu, L.;

Negrila, C.; Bacalum, M.; Ungureanu,

C.; Barbinta-Patrascu, M.E.

Correction: Zgura et al. Cytotoxicity,

Antioxidant, Antibacterial, and

Photocatalytic Activities of $\mathrm{ZnO}-\mathrm{CdS}$

Powders. Materials 2020, 13, 182.

Materials 2021, 14, 7713. https://

doi.org/10.3390/ma14247713

Received: 2 December 2021

Accepted: 7 December 2021

Published: 14 December 2021

Publisher's Note: MDPI stays neutral with regard to jurisdictional claims in published maps and institutional affiliations.

Copyright: (c) 2021 by the authors. Licensee MDPI, Basel, Switzerland. This article is an open access article distributed under the terms and conditions of the Creative Commons Attribution (CC BY) license (https:// creativecommons.org/licenses/by/ $4.0 /)$.

\section{Error in Figure}

In the original publication [1], there was a mistake in Figure 10 as published due to the duplication of a picture. The corrected Figure 10 appears below.
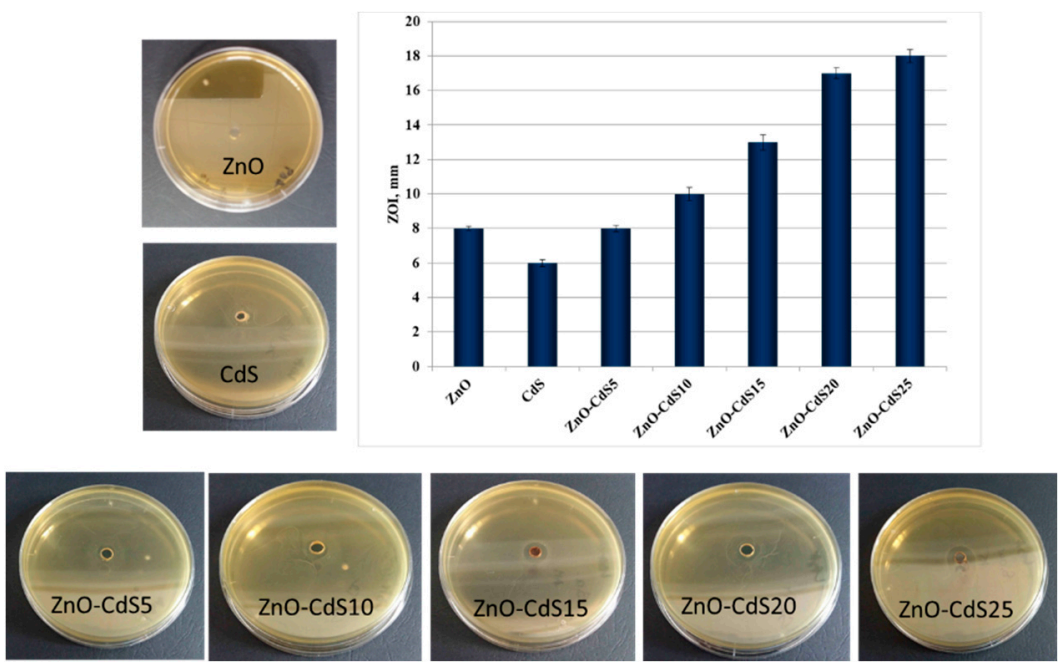

Figure 10. Antibacterial activity of $\mathrm{ZnO}, \mathrm{CdS}$, and $\mathrm{ZnO}-\mathrm{CdS}$ powders against Escherichia coli ATCC 8738 and the corresponding zone of inhibition.

The authors apologize for any inconvenience caused and state that the scientific conclusions are unaffected. The original publication has also been updated.

\section{Reference}

1. Zgura, I.; Preda, N.; Enculescu, M.; Diamandescu, L.; Negrila, C.; Bacalum, M.; Ungureanu, C.; Barbinta-Patrascu, M.E. Cytotoxicity, Antioxidant, Antibacterial, and Photocatalytic Activities of $\mathrm{ZnO}-\mathrm{CdS}$ Powders. Materials 2020, 13, 182. [CrossRef] [PubMed] 